\title{
Effect of Social Media Used by Medical Professionals in Facilitating the Treatment of Chronic Illnesses
}

\author{
Hossam Alakhrass' ${ }^{1}$, , Waleed Alenazi $^{2}$, Sameh Kamal Al-Akhrass ${ }^{3}$ \\ ${ }^{1}$ Department of Public Health, Maternity and Children's Hospital, Ministry of Health, Dammam, KSA \\ ${ }^{2}$ Diabetes Department, Haft Al-Batin, Ministry of Health, Haft Al-Batin, KSA \\ ${ }^{3}$ Department of Occupational Health, Ministry of Health, Dammam, KSA \\ Email: drhossamk@hotmail.com,dr.enazy@live.com,sal-akhrass@moh.gov.sa
}

How to cite this paper: Alakhrass, $\mathrm{H}$., Alenazi, W. and Al-Akhrass, S.K. (2020) Effect of Social Media Used by Medical Professionals in Facilitating the Treatment of Chronic Illnesses. Health, 12, 127-131. https://doi.org/10.4236/health.2020.122011

Received: December 18, 2019

Accepted: February 9, 2020

Published: February 12, 2020

Copyright (C) 2020 by author(s) and Scientific Research Publishing Inc. This work is licensed under the Creative Commons Attribution International License (CC BY 4.0).

http://creativecommons.org/licenses/by/4.0/

\begin{abstract}
The objective of this research is to describe the effect of social media use by medical professionals in facilitating the treatment of chronic illnesses in chronically ill individuals. This study focuses on the prominent social media used by medical professionals and the way it is used to manage health conditions of chronically ill individuals.
\end{abstract}

\section{Keywords}

Diabetes, Glucose, Digital, Social Media, Technology, Chronic Illness

\section{Introduction}

Digital communication and networks are changing the way people manage their lives, and this includes how they access healthcare services and how services are delivered to them. Social media use in the health care industry has become more prominent in recent years as it contributes to a healthy culture and stimulates competition and wellbeing. It can also be used to communicate health care advice, promote a healthy lifestyle, and communicate medical emergencies as well as facilitate post-clinical communications [1].

One group of patients that relies on social media to manage their condition is chronic disease sufferers, defined as individuals who suffer from chronic conditions for a period of more than one year who require periodic medical attention. Social media not only provide a health communication outlet for the sufferers, but also facilitate their communication with their clinicians. In the United States 
(US) alone, $45 \%$ of the population suffers from chronic illnesses that constitute a noticeable portion of the annual health care costs. With the popularity of social media such as YouTube, Twitter and Facebook, it is natural to ask how these social media platforms can be used by medical professionals in order to facilitate the treatment of chronic illnesses [1].

\section{Literature Review}

A 2016 research on social media use in healthcare by performing a systematic literature review has categorized six uses of social media by patients as emotional, information, esteem, network support, social comparison and emotional expression and it has been concluded that these six uses leads to seven identified types of effects on patients which are diminished subjective well-being, enhanced psychological well-being and enhanced subjective well-being, addiction to social media, improved self-management and control and loss of privacy, and being targeted for promotion. This research has also concluded that social media communication led to a more balanced communication by giving healthcare professional and patient more symmetric conversation leading to equal communication time as well as providing suboptimal interaction among the patient and professionals [1].

A study on the effects of chronic disease management using social media performed in 2013 reviewed the available researches on health outcomes and related effects of using social media and concluded that the effects of social media on such patients are positive. However, this study did not include specific social media and there is lack of evidence on the effects of social media on chronic disease management as a whole [2].

\section{Methodology}

The databases used to implement the necessary data analysis for the conclusion of the research questions were constituted from literature review that are general in scope and that contain relevant publications available on scholarly research resources such as in MEDLINE and PubMed. The data gathered has been of qualitative nature and as a result meta-analysis was performed to understand the popularity of the social media and the most frequent outcomes which are indicative of how these media are and can be used to facilitate treatment of chronically ill individuals [2].

\section{Results}

The data table containing the researchers found by the review is presented below.

It is necessary to mention that each of the studies included in the data are either a study that includes multiple studies or includes multiple factors given multiple subjects which serve as a broader base of data for the research hypothesis as seen in Table 1 . 
Table 1. Meta analysis of accessed research.

\begin{tabular}{|c|c|c|c|c|c|}
\hline No & Publication & $\begin{array}{c}\text { Type of } \\
\text { chronic disease }\end{array}$ & Type of social media & $\begin{array}{l}\text { Duration of } \\
\text { intervention by } \\
\text { the social media }\end{array}$ & $\begin{array}{c}\text { Research } \\
\text { Implementation } \\
\text { Country }\end{array}$ \\
\hline 1 & (Anhøj, Nielsen, \& Nordfeldt, 2011) [3] & & Discussion forum & 30 days & Denmark \\
\hline 2 & (Gupta et al., 2012) [4] & Asthma & $\begin{array}{l}\text { Collaboration through } \\
\text { social media }\end{array}$ & 21 days & Canada \\
\hline 3 & $($ Broom, 2005) [5] & Prostate cancer & Online support group & - & Australia \\
\hline 4 & $\begin{array}{l}\text { (Gómez-Zúñiga, Fernandez-Luque, Pousada, } \\
\text { Hernández-Encuentra, \& Armayones, 2012) [6] }\end{array}$ & Varied & YouTube & - & varied \\
\hline 5 & (Wentzer \& Bygholm, 2013) [7] & Varied & Support group & - & Denmark \\
\hline
\end{tabular}

\section{Discussion}

Two researches included on asthma have been due to the fact that asthma is the most common chronic childhood condition and both of the included research have shown that on a randomized control trial the social media does indeed improve the management of asthma related incontinences although not in all aspects. The research performed by Broom on subjects with prostate cancer in Australia depicts the challenges of engaging both the patients and the professionals. Patients often perceive interventions through social media to be lacking professionalism, genuine information and deem it less influential than in person care. Professionals also regard online platforms to be a threat to their professional status. Therefore, it is implied that for social media to be effectively used in managing chronically ill patients, both professionals and patients need to trust and commit themselves to achieving the desired outcome through these new means. The results of this research can also be represented by subject characteristics.

The existing research on usage of YouTube as a means to express chronic conditions experience by patients helps other individuals with the same experience to relate and manage their condition better even though this may cause loss of privacy for the individuals sharing their experience as seen in Table 2. This importance of this research lies in the fact that YouTube is one of the most popular social media outlets and that the individuals in this survey have been suffering from a chronic disease in general and the research is not limited to a specific category of chronic diseases. The subject characteristics of this research are shown in Table 3.

The last included research in the study as seen in Table 3, showed that specific social media outlets which are supervised by the professionals also does help chronically ill patients. This research does not include the data for the gender and ages of the subjects but given in there have been no age or gender restriction for 246 participants who participated in 33 online support groups.

From the meta-analysis we can conclude that the social media whether specialized or general purposed when used by professionals to communicate with chronically ill patients does help in management of their help issues. The studies in the meta-analysis also show that the results are not relevant to only a specific 
Table 2. Subject characteristics of research by broom.

\begin{tabular}{ccc}
\hline Age & Ethnicity & Social Media Intervention \\
\hline $40-85$ & $\begin{array}{c}\text { Anglo Australian, Irish, British, } \\
\text { Italian, Polish, New Zealand }\end{array}$ & Internet and online communities \\
\hline
\end{tabular}

Table 3. Subject characteristics of the research by Gómez-Zúñiga, Fernandez-Luque, Pousada, Hernández-Encuentra, \& Armayones.

\begin{tabular}{cccc}
\hline Age & Sex & Disease & Social Media Intervention \\
\hline 29 & Female & Multiple Sclerosis & YouTube \\
31 & Male & Diabetes & YouTube \\
32 & Female & Diabetes & YouTube \\
47 & Male & Multiple Sclerosis & YouTube \\
\hline
\end{tabular}

country which implies the reach and potential of such a management methodology and perhaps most important result is that the effect of social media is also not bond to a specific age group, gender or ethnicity.

The performed meta-analysis also showed that social media can positively impact chronic patients with multiple varieties of conditions even though the effect of social media on each type of chronic condition as well as its significance relative to in person care of professionals remains to be studied.

\section{Conclusions}

In conclusion, available research implies that the most common chronic diseases through the most popular social media when supervised by professionals can in fact help to reduce and manage conditions related to chronic diseases. These researches also show that the positive outcomes are not related to specific ethnicity, age group or gender.

More research however is required to study the optimal social media and the challenges that prevent their potential positive outcomes. One such issue is that some chronic patients perceive social media interventions such as online groups to be deceptive and not of high value when compared to human professional interaction and as a result they view computer-mediated communication to be not effective and problematic.

\section{Conflicts of Interest}

The authors declare no conflicts of interest regarding the publication of this paper.

\section{References}

[1] Smailhodzic, E., Hooijsma, W., Boonstra, A. and Langley, D.J. (2016) Social Media Use in Healthcare: A Systematic Review of Effects on Patients and on Their Relationship with Healthcare Professionals. BMC Health Services Research, 16, 442. https://doi.org/10.1186/s12913-016-1691-0 
[2] Merolli, M., Gray, K. and Martin-Sanchez, F. (2013) Health Outcomes and Related Effects of Using Social Media in Chronic Disease Management: A Literature Review and Analysis of Affordances. Journal of Biomedical Informatics, 46, 957-969. https://doi.org/10.1016/j.jbi.2013.04.010

[3] Anhøj, J., Nielsen, L. and Nordfeldt, S. (2011) Evaluation of a Web-Based Asthma Self-Management System: A Randomised Controlled Pilot Trial. Journal of Medical Internet Research, 15, 17.

[4] Gupta, S., Wan, F., Ducharme, F., Chignell, M., Lougheed, M. and Straus, S. (2012) Asthma Action Plans Are Highly Variable and Do Not Conform to Best Visual Design Practices. Annals of Allergy, Asthma \& Immunology, 108, 260-265.e2. https://doi.org/10.1016/j.anai.2012.01.018

[5] Broom, A. (2005) The eMale. Journal of Sociology, 41, 87-104. https://doi.org/10.1177/1440783305050965

[6] Gómez-Zúñiga, B., Fernandez-Luque, L., Pousada, M., Hernández-Encuentra, E. and Armayones, M. (2012) ePatients on YouTube: Analysis of Four Experiences from the Patients' Perspective. Medicine 2.0, 1, e1.

https://doi.org/10.2196/med2.2039

[7] Wentzer, H.S. and Bygholm, A. (2013) Narratives of Empowerment and Compliance: Studies of Communication in Online Patient Support Groups. International Journal of Medical Informatics, 82, e386-e394. https://doi.org/10.1016/j.ijmedinf.2013.01.008 